\title{
Assessing cross-sectoral climate change impacts, vulnerability and adaptation: an introduction to the CLIMSAVE project
}

\author{
P. A. Harrison - I. P. Holman • P. M. Berry
}

Received: 11 August 2014 / Accepted: 3 January 2015 / Published online: 17 January 2015

(C) Springer Science+Business Media Dordrecht 2015

\begin{abstract}
Quantitative participatory exploration of the many complex issues surrounding cross-sectoral climate change impacts, vulnerability and adaptation under uncertain futures is dependent on the provision, in some form, of scenarios and scenario outputs. However, the normal provision by the research community of pre-defined scenario outputs results in a lack of flexibility for stakeholders regarding choice of climate models, scenarios, scenario quantification and output indicators which in turn can lead to a lack of trust. This Special Issue describes the development and application of a web-based interactive simulation and display environment, called the CLIMSAVE Integrated Assessment (IA) Platform, which provides a holistic (cross-sectoral, climate and socio-economic change) modelling framework. The IA Platform guides the user through simulation of (1) potential impacts under scenarios of climate and/or socio-economic change, (2) identification of sectoral and multi-sectoral vulnerability 'hotspots' either before or after adaptation, (3) the potential for adaptation to reduce impacts within the capital constraints of the selected scenario(s), and (4) the cost-effectiveness of adaptation measures. The Special Issue explores how the IA Platform has been: (i) designed to provide a user-friendly, intuitive and facilitating, rather than predictive or prescriptive, environment for users; and (ii) utilised to quantitatively explore a diverse range of uncertain futures across Europe.
\end{abstract}

\section{Introduction}

Adaptation to the changing climate is an urgent policy issue which has high stakes for current and future societies. Climate change adaptation has become increasingly important at institutional and political levels in Europe since the publication of "An EU Strategy on Adaptation to Climate Change" (EC 2013), which recognises that mitigation alone, though still of primary

This article is part of a Special Issue on "Regional Integrated Assessment of Cross-sectoral Climate Change Impacts, Adaptation, and Vulnerability" with Guest Editors Paula A. Harrison and Pam M. Berry.

P. A. Harrison $(\bowtie) \cdot$ P. M. Berry

Environmental Change Institute, Oxford University Centre for the Environment, South Parks Road, Oxford OX1 3QY, UK

e-mail: Paula.Harrison@ouce.ox.ac.uk

I. P. Holman

Cranfield Water Science Institute, Cranfield University, Cranfield Bedford MK43 0AL, UK 
importance, no longer constitutes an effective climate change policy. Adaptation policymaking is a multi-level issue. Effective adaptation emerging out of decisions made by local community actors needs to be strongly supported by an empowering national and EU institutional setting which facilitates coordination and knowledge sharing among the EU Member States (Pataki et al. 2012). However, the EU White Paper on a European adaptation framework (EC 2009) highlighted that information and research on climate change impacts and vulnerability in Europe remains fragmented and is not effectively shared across sectors and decision-making levels. Knowledge integration is further hindered by the provision of predefined scenario outputs by the research community. This presents a lack of flexibility for stakeholders as choices regarding scenarios, scenario quantification, sectors and output indicators have all been pre-determined by the researchers, which in turn can lead to a lack of transparency and trust.

To build trust and user relevance, it is important that stakeholders be participants in, rather than observers of, impact and adaptation studies (Turnpenny et al. 2004; Salter et al. 2010). However, there are relatively few stakeholder-led quantitative studies which undertake a holistic assessment of the effects of our changing climate, taking explicit account of crosssectoral interactions and the influence of socio-economic and political changes in addition to climate changes (Holman et al. 2008; Harrison et al. 2013). There is, therefore, a need for participatory IA tools to facilitate this process. The CLIMSAVE (Climate Change Integrated assessment Methodology for cross-Sectoral Adaptation and Vulnerability in Europe) project developed and applied such a tool for Europe. The user-friendly, interactive web-based tool allows stakeholders to quantitatively assess climate change impacts and vulnerabilities for a range of sectors: agriculture, forests, biodiversity, coasts, water resources and urban development. The linking of models for the different sectors enables stakeholders to see how their interactions could affect changes to the rural and urban landscape of Europe. The tool also enables stakeholders to explore adaptation strategies for reducing climate change vulnerability, discovering where, when and under what circumstances such actions may help, within the capital constraints of the selected scenario(s). It further highlights the cost-effectiveness and cross-sectoral benefits and conflicts of different adaptation options and enables uncertainties to be investigated to better inform the development of robust policy responses. The tool has not been designed to be a decision support system, but rather to be an interactive, exploratory tool that raises awareness of the complex issues surrounding adaptation to climate change and facilitates a discourse between different groups of stakeholders on key issues or trade-offs that need to be considered in adaptation planning.

This Special Issue introduces the need for regional integrated assessments of future (climate and socio-economic) change, the role of stakeholders in such studies, the importance of considering cross-sectoral interactions and provides an overview of key findings from applying the CLIMSAVE integrated assessment tool to assess the crosssectoral implications of climate change impacts, vulnerability and adaptation in a series of 17 papers (Fig. 1).

\section{What is CLIMSAVE?}

CLIMSAVE was a research project funded by the European Union from 2010 to 2013. It was a large multi-institution endeavour involving 18 European and international partners from 13 countries, including small and medium size enterprises and specialists in stakeholder engagement and workshop facilitation. The main aim of CLIMSAVE was to deliver an integrated methodology to assess cross-sectoral climate change impacts, vulnerability and adaptation. It 


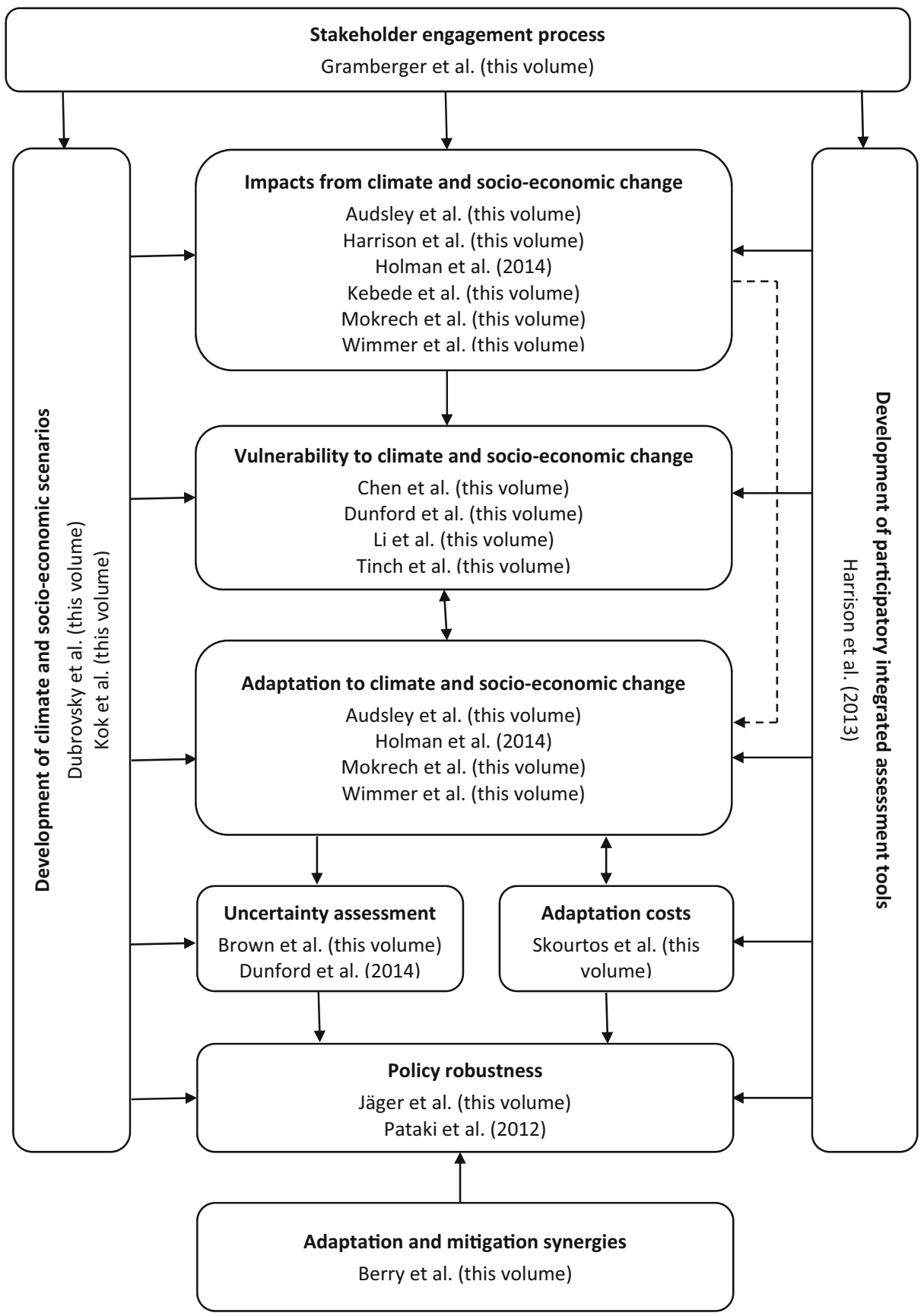

Fig. 1 The methodological components of the CLIMSAVE project and references to publications

aspired to put science at the service of stakeholders and policy-makers by providing a webbased platform that is freely accessible to all users, enabling them to undertake their own improved IA of climate change impacts, vulnerability and cost-effective adaptation measures 
for key sectors in Europe. Comparisons with similar research in China were also drawn. There were six specific objectives:

1. To develop an IA Platform which includes linkages and feedbacks between key landscape sectors;

2. To integrate stakeholder input into climate change impacts and adaptation research through the development of participatory socio-economic scenarios which are integrated into the IA Platform along with a range of climate scenarios;

3. To apply the IA Platform to assess climate change impacts and adaptation options across different sectors and ecosystem services, along with consideration of their uncertainties;

4. To identify vulnerability hotspots through metrics of impacts and coping capacity across sectors within the IA Platform;

5. To provide information on the cost-effectiveness of adaptation measures within the IA Platform;

6. To analyse the policy and governance context for adaptation, and synergies and trade-offs between adaptation and mitigation, in order to inform appropriate policy options.

\section{The CLIMSAVE approach}

Previous research on climate change impacts, vulnerability and adaptation methods has demonstrated that there is a need for participatory modelling tools, but only if they are perceived by stakeholders as being both credible, accurate, easy to understand and appropriate (Holman et al. 2008). This implies moving away from participatory design approaches (Dittrich and Lindeberg 2004) that focus on software-based issues of user and usability requirements (Pahl 2004; Dempsey and Fisher 2005; Hanson et al. 2006) to a stakeholder-led research paradigm where stakeholders are embedded in and through the research process such that the necessary trust in, and legitimacy of, the tool is developed. Although there have been a very small number of previous participatory modelling projects (such as the Regional Impact Simulator; Holman and Harman 2008) that have attempted such an approach, the depth of stakeholder engagement throughout CLIMSAVE is unlike earlier studies. The CLIMSAVE process (Fig. 2) combined an objective approach to stakeholder selection (Gramberger et al. this volume), participatory scenario development that included both qualitative and quantitative fuzzy set theory approaches (Kok et al. this volume), iterative IA Platform design (addressing issues of functionality, cognitive accessibility and interactivity), and the participatory identification, testing and selection of robust adaptation options.

It is increasingly recognised that an integrated approach is needed to address environmental problems, which moves away from a sectoral (or silo) view of impacts to recognising the importance of cross-sectoral interactions. CLIMSAVE addressed this in the development and linking of a series of sectoral models, in which data were passed down a model chain representing cross-sectoral interactions (Fig. 3). For example, the spatial allocation of crops to agricultural land across Europe is not only influenced by the demand for food (determined by the socio-economic scenario) and future crop yields (simulated by the crop model), but also by land suitability restrictions (due to flooding, soil limitations and ecological protection) and the competing demands for water and land (from urban development and forestry). 

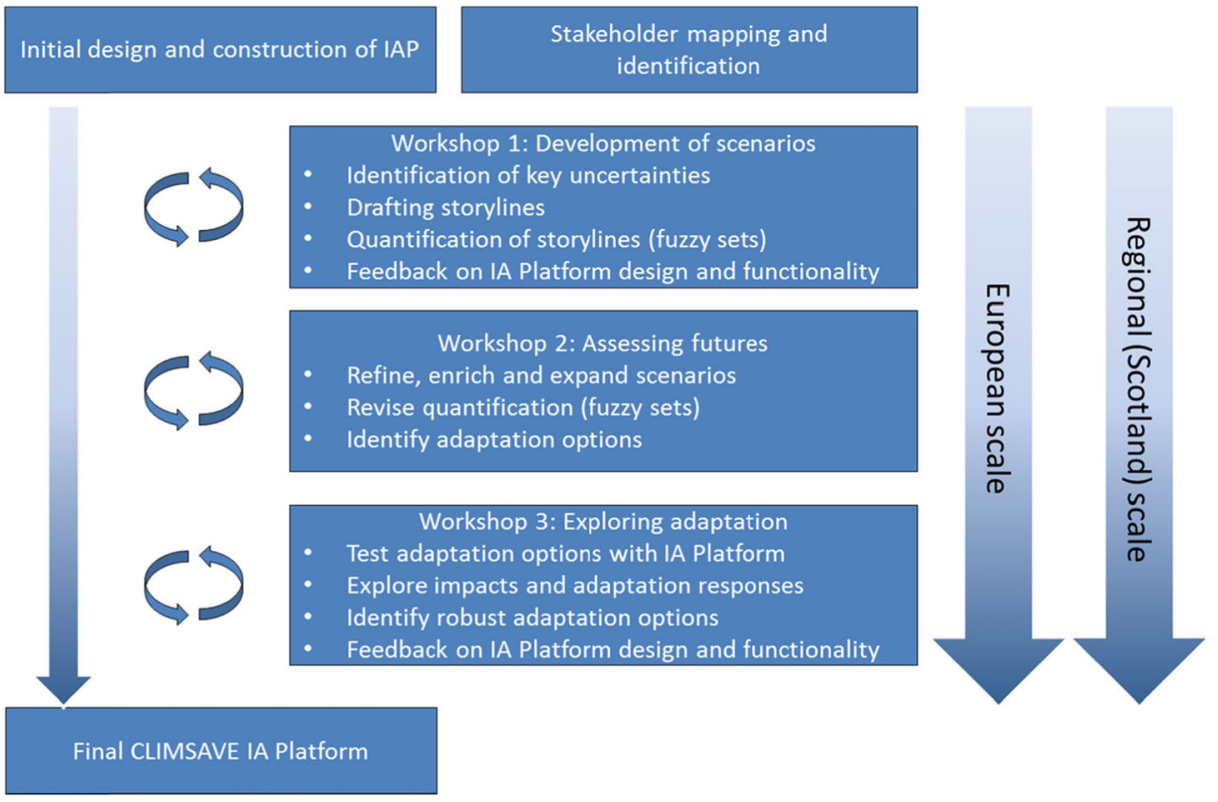

Fig. 2 Overview of the CLIMSAVE approach and the role of stakeholders. Adapted from Harrison et al. (2013)

The CLIMSAVE approach, including both the stakeholder workshops and IA Platform development, was implemented at two scales: for Europe and a regional case study (Scotland).

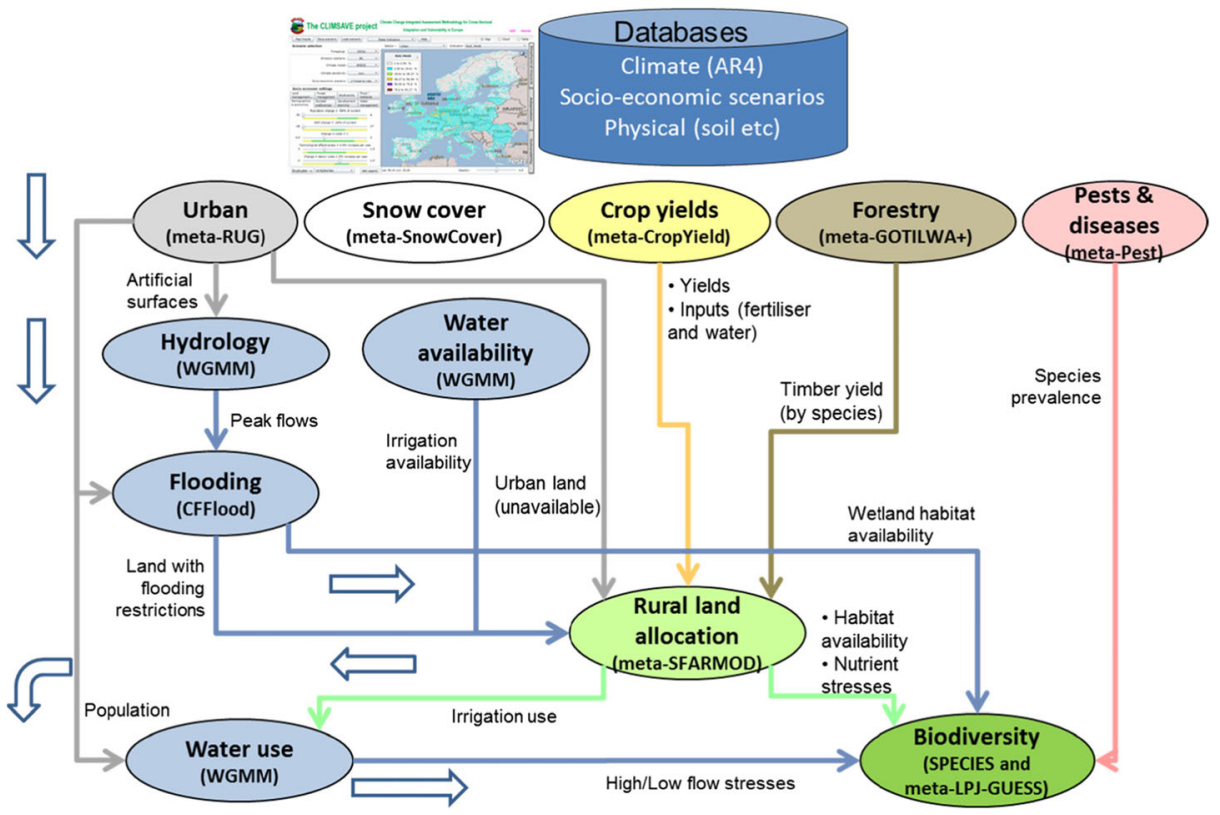

Fig. 3 Schematic figure showing the data transfers between the models within the CLIMSAVE IA Platform. Adapted from Harrison et al. (2013) 
This Special Issue is focused on Europe, but details of the Scottish results are given in Holman et al. (2014) and Harrison and CLIMSAVE consortium (2013).

\subsection{Climate and socio-economic scenarios}

Uncertainty is inherent and unavoidable when considering the impacts of future climate and socio-economic change on Europe. As a result, these high level uncertainties had to be explicitly taken into account within the CLIMSAVE process, as adaptation options that are robust to multiple climate (Dubrovsky et al. this volume) and socio-economic (Kok et al. this volume) scenarios are needed to inform future policy (Jäger et al. this volume). However, the incorporation of uncertainty into participatory tools, such as the CLIMSAVE IA Platform, has to balance the conflicting pressures of recognising the diverse sources of uncertainty and their magnitudes against providing so many degrees of freedom that the user gets lost or confused.

It can be impractical to include outputs from all Global Climate Models (GCMs) in participatory tools or in large-domain climate impact assessments, so (Dubrovsky et al. this volume) present a novel methodology that was used in CLIMSAVE for identifying a representative subset of GCMs for inclusion in the IA Platform. An objective methodology to identify a subset of five GCMs, based on both the quality of the GCMs' simulation of historical seasonality in climate and the ability of the subset to represent the full inter-GCM variability, was developed and compared with a subjective approach based on expert judgment.

The stakeholder-led CLIMSAVE socio-economic scenarios were developed in four broad stages, described in Kok et al. (this volume), through a series of professionally facilitated workshops based on: (i) identifying the main concerns about future developments (EEA 2010); (ii) selecting two key uncertainties for the "scenario axes technique" (Van't Klooster and Van Asselt 2006) to sketch four skeleton scenarios; (iii) drafting and refinement of the scenario storylines and associated qualitative products; and (iv) quantification of scenario variables using fuzzy set theory (Alcamo 2008). The participatory process resulted in a broad range of futures which are envisioned to be plausible for Europe:

- 'We are the World' is the most prosperous future scenario, combining high levels of innovation and gradual economic development. Effective governments change the focus from GDP to well-being, which leads to a redistribution of wealth, and thus to less inequality and more (global) cooperation.

- 'Icarus', by contrast, focuses on short-term policy planning, which together with a gradually stagnating economy, leads to the disintegration of the social fabric and to a shortage of goods and services.

- 'Should I Stay or Should I Go' is characterised by actors failing to address a rollercoaster of economic crises, which leads to an increased gap between rich and poor, to political instability and to conflicts. In this scenario most citizens live in an insecure and unstable world.

- 'Riders on the Storm' is equally hit hard by continual economic crises. However, actors successfully counter the situation through investment in renewable energies and green technologies. In this scenario Europe is an important player in a turbulent world.

The climate and socio-economic scenarios have not been formally linked in the IA Platform. This allows the user to explore scenario combinations that are internally consistent through their associated carbon emissions, or socio-economic scenarios in which European emission trajectories are divergent from global trends. 
3.2 The CLIMSAVE integrated assessment platform

\subsubsection{Development of the IA platform}

Developing a useful supporting tool that informs stakeholders' adaptation thinking and planning requires balancing Platform complexity (as given by the choices available to users regarding input scenarios and settings) and stakeholder information needs with Platform design (Harrison et al. 2013; Holman et al. 2013), such that useful and credible output indicators are provided at a range of appropriate scales (Harrison et al. this volume; Holman et al. 2014; Kebede et al. this volume). It also needs to be scientifically robust, recognising that the European rural and urban landscape in its broadest sense is a complex socio-ecological system with multiple interactions and feedbacks between sub-systems (Audsley et al. this volume; Brown et al. this volume; Harrison et al. this volume; Kebede et al. this volume; Mokrech et al. this volume; Wimmer et al. this volume), and one in which capital (social, human, manufactured, natural and financial) availability imposes limits on short-term coping and longer-term adaptation responses to environmental change (Dunford et al. this volume; Skourtos et al. this volume; Tinch et al. this volume).

The four screens within the IA Platform (Fig. 4) have incorporated all of these elements in order to facilitate a structured exploration of impacts, vulnerability, adaptation and adaptation cost-effectiveness:

Impacts screen (Fig. 4a) This screen is used to investigate how different amounts of future climate and socio-economic change may affect agriculture, forests, biodiversity, coasts, water resources and urban development, considering a large range of sectoral and ecosystem service indicators. It can be used to:

- Carry out a sensitivity analysis under the baseline / current climate to investigate indicator responses to changes in scenario settings;

- Investigate the effects of uncertainty in climate models, greenhouse gas emissions scenarios and climate sensitivity by selecting different scenarios in conjunction with the baseline socio-economic scenario;

- Explore the effects of combined climate and socio-economic uncertainty through different combinations of climate and CLIMSAVE socio-economic scenarios;

- Explore the effects of uncertainty within a socio-economic scenario, as given by the green (or credible) uncertainty ranges on the sliders for the scenario variables. These values are consistent with the assumptions within each scenario;

- Model impacts in relation to "user-defined" socio-economic scenarios, where scenario variables are moved outside of the green uncertainty range.

Vulnerability screen (Fig. 4b) This screen is used to investigate which areas or 'hotspots' in Europe may be vulnerable to climate change under a given socio-economic scenario, before and/or after adaptation. Vulnerability is defined as the degree to which a system is susceptible to, or unable to cope with, the immediate adverse effects of climate change. The Vulnerability screen combines impacts before (potential impact) or after adaptation (residual impact), which are taken from the outputs of the "Impacts" and "Adaptation" screens, respectively, with coping capacity to derive vulnerability. The screen can be used to map vulnerability to single or multiple ecosystem service indicators covering food, water, flooding, biodiversity, cultural/ aesthetic aspects and land use diversity. 
a

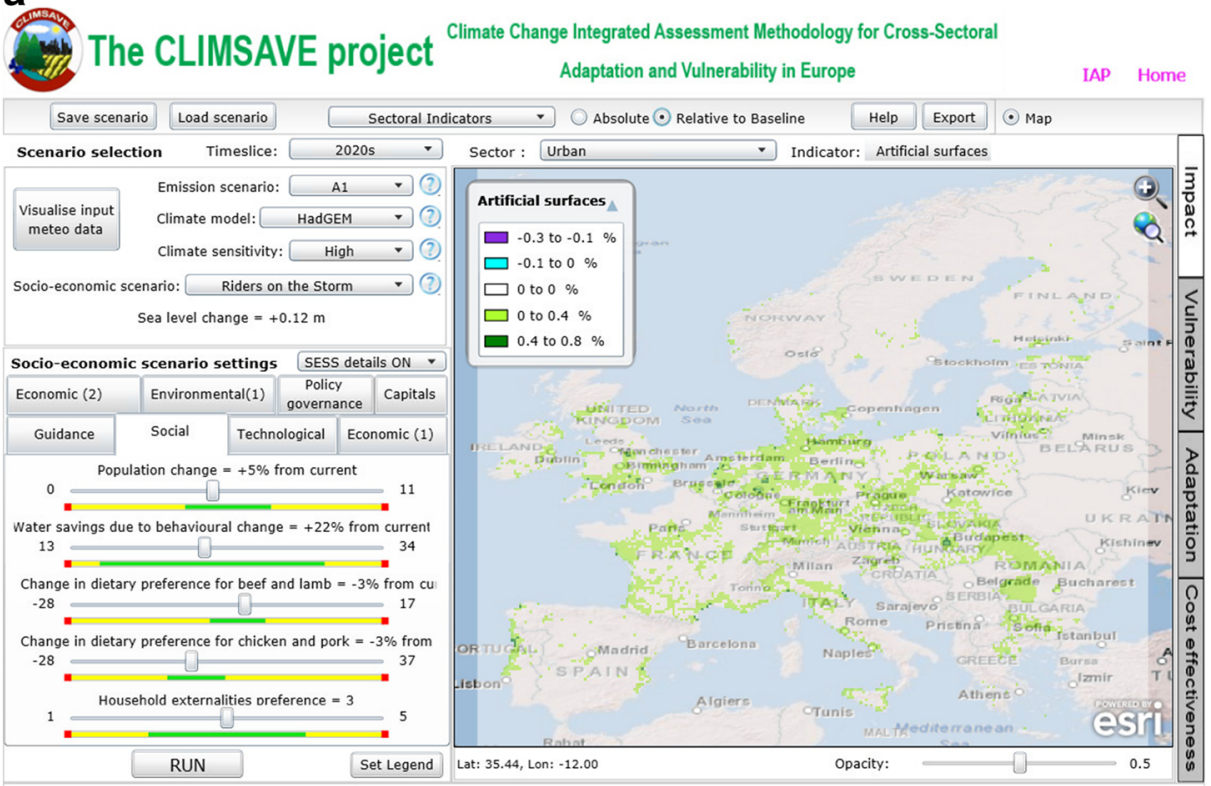

RUG ended; SNOW ended; WGMMhU1 ended; PESTS ended; FLOOD ended; SFARMMOD ended; WGMMU2 ended; LPJ ended; SPECIES ended;

b

\section{The CLIMSAVE project}

Climate Change Integrated Assessment Methodology for Cross-Sectoral Adaptation and Vulnerability in Europe

IAP Home
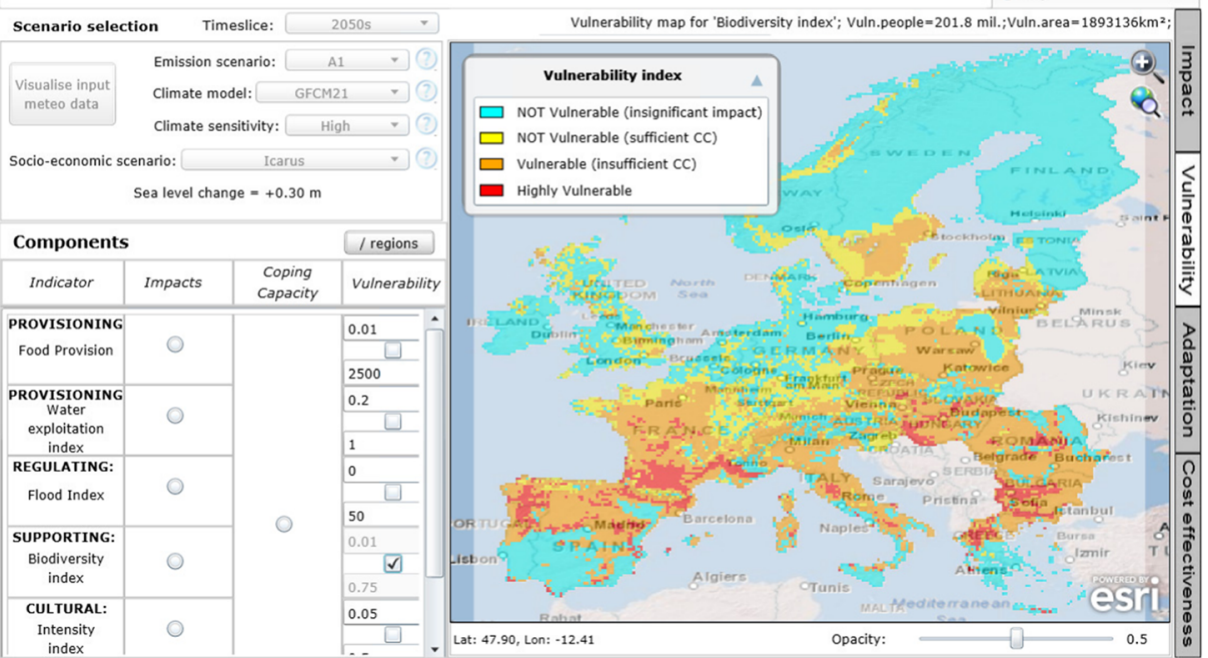

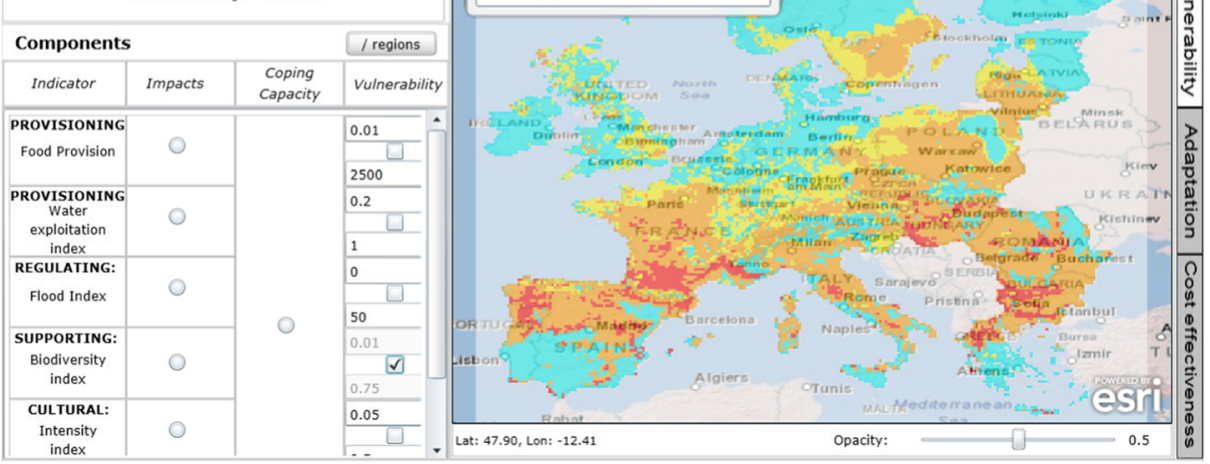

Fig. 4 Screenshots of the four screens of the CLIMSAVE IA Platform: a Impacts screen; b Vulnerability screen; c Adaptation screen; and d Cost-effectiveness screen

Adaptation screen (Fig. 4c) This screen is used to investigate how adaptation can reduce the longer-term impacts of climate change in a scenario. The amount of allowable adaptation (as 


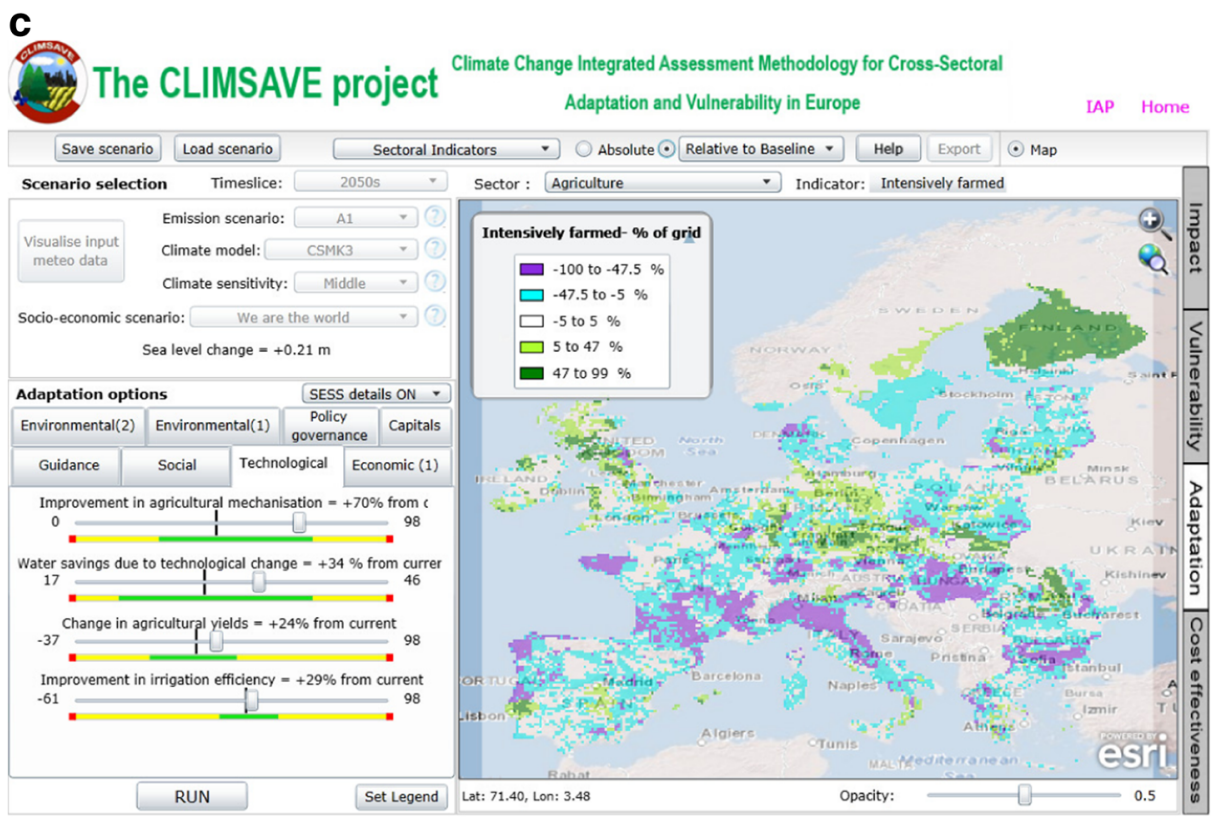

d

The CLIMSAVE project Climate Change Integrated Assessment Methodology for Cross-Sectoral

IAP Home

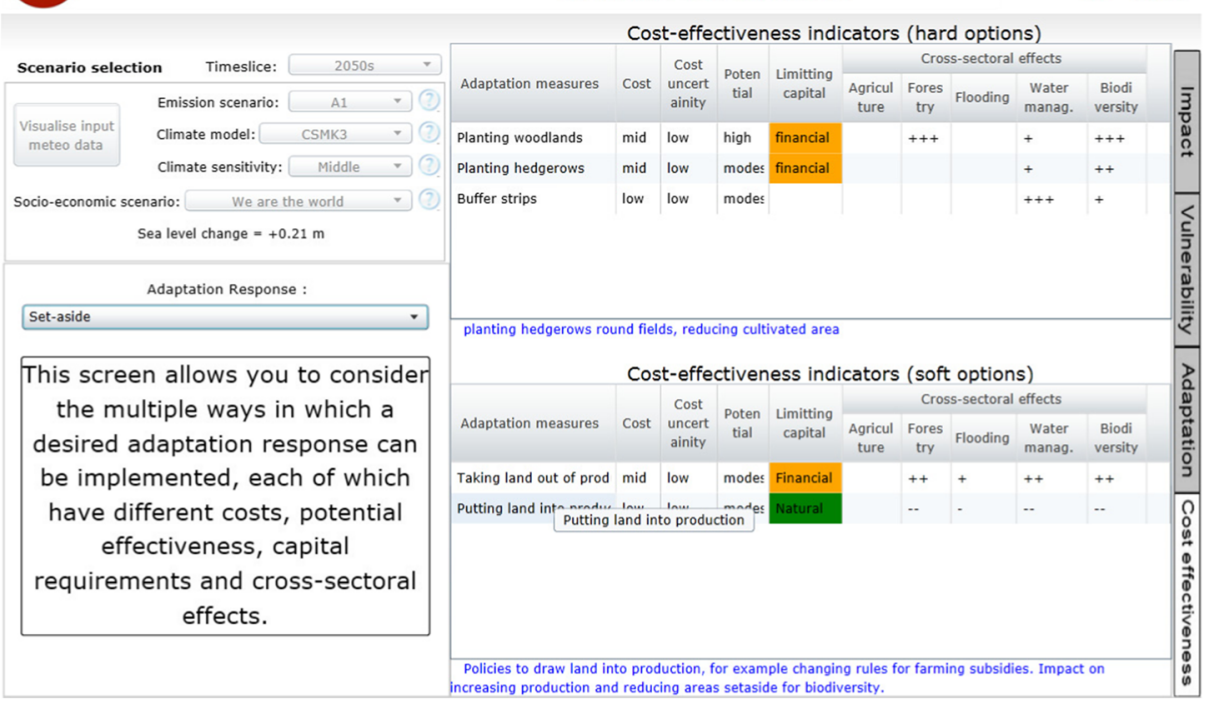

Fig. 4 (continued)

given by the size of the green zone on the adaptation sliders) is limited according to both the likely importance of the given adaptation response within the socio-economic scenario and the adaptive capacity of the scenario, based on the availability of the limiting capital for a given adaptation response. The screen can be used to: 
- Assess whether adaptation responses can fully or partially address adverse impacts, within the constraints of the socio-economic scenario;

- Assess whether increased adaptive capacity (as given by the availability of capitals) is required to adequately adapt to climate change.

Cost-effectiveness screen (Fig. 4d) This screen is used to consider the relative cost and effectiveness of adaptation measures to reduce the impacts of climate change. An extensive database of adaptation costs drawing on hundreds of published studies from around the world was collated to inform the costs, and uncertainty in costs, of 'hard' adaptation measures (Skourtos et al. 2013). The costs of 'soft' adaptation measures and the potential of hard and soft options to contribute to overall effective adaptation in a sector were identified using expert judgement. This screen can be used to:

- Evaluate the range of hard and soft adaptation measures that might be available to implement the adaptation response modelled within the "Adaptation" screen;

- Consider the multiple facets of adaptation planning, considering the costs, effectiveness, availability of limiting capitals and the cross-sectoral effects (both win-wins and unintended consequences).

\subsubsection{Synthesis of results from application of the IA platform}

The application of the IA Platform to study the effects of climate and socio-economic change on sectoral and cross-sectoral impacts, adaptation and vulnerability is described in several papers within this Special Issue. New insights into the complex interactions between different sectors are discussed by Kebede et al. (this volume), who use sensitivity analysis to assess sectoral interdependencies under a range of systematic and independent changes in climate and socio-economic variables, and by Harrison et al. (this volume), who analyse cross-sectoral interactions for a wide range of combined scenario futures. Those sectors most sensitive to changes, the mechanisms and directions of sensitivity, the form and magnitudes of change, and the relative importance of the key drivers across sectors are identified by Kebede et al. (this volume). This assessment enables a better understanding of the nature of complex cross-sectoral interactions, providing essential information for interpreting impacts from future scenarios. For example, Harrison et al. (this volume) highlight how Europe will be significantly influenced by future climate and socio-economic change, including increases in urban development in most scenarios which indirectly result in increases in the number of people affected by a 1 in 100 year flood event in western and northern Europe. Furthermore, food production was found to generally increase across Europe at the expense of forest area and unmanaged land, leading to increases in biodiversity vulnerability and water exploitation in southern and eastern Europe.

More specific assessment of impacts and adaptation have been undertaken for flooding (Mokrech et al. this volume), water allocation (Wimmer et al. this volume) and agricultural and forest land use (Audsley et al. this volume), each taking account of cross-sectoral interactions. Mokrech et al. (this volume) found that flood impacts 
generally increase in the future, especially due to sea-level rise, and that impacts of more extreme scenarios can only be reduced to current levels by major adaptation measures, such as upgrading flood protection by $500 \%$ or more from baseline levels. Wimmer et al. (this volume) show that significant water resource shortages may result from climate and socio-economic change in many regions of Europe, particularly in the Mediterranean. Assessment of the performance of multiple water allocation schemes, in balancing adverse impacts across water use sectors and aquatic ecosystems, indicates that cross-sectoral impacts are lowest if either the domestic or manufacturing sector is assigned higher priority than agriculture. Audsley et al. (this volume) highlight the advantages of combining simplified models of crop and forest yields with farm profitability and water availability to predict changes in European land use. The fast simulation times associated with such meta-models allow rapid iteration and identification of the most important driving factors in matching supply and demand for food and water. The authors found that changes in population, yield improvement due to technology and agronomy, and food imports have the greatest impact, particularly when compared with climate.

Mokrech et al. (this volume), Wimmer et al. (this volume) and Audsley et al. (this volume) also found that the effectiveness of adaptation options in reducing potential impacts is often limited by the adaptive capacity of societies under the different scenarios. Tinch et al. (this volume) discuss how different adaptation options have different requirements for implementation, some of which might not be feasible under the conditions of particular socio-economic scenarios. They demonstrate how an index of adaptive capacity can be developed using a capitals (human, social, manufactured, financial) model of societal wealth and incorporated within integrated assessment models, such as the CLIMSAVE IA Platform. As part of the implementation of this approach, stakeholder workshops and sector-specific expert judgement were used to estimate the availability of capital stocks within any given socio-economic scenario (Kok et al. this volume). These were compared with capital requirements for specific adaptation options to determine the levels of adaptation that are 'plausible' in the sense of being consistent with scenario assumptions.

A capitals approach was also used to develop an index of coping capacity in Europe for mapping vulnerability 'hotspots' (Dunford et al. this volume; Tinch et al. this volume). Results from combining coping capacity with potential impacts suggest that human well-being is most at risk from water stress and biodiversity loss in southern Europe, and from a lack of food provision and land use diversity in northern Europe. The European assessment was compared with results from applying a similar capitals approach for assessing adaptive capacity in China (Chen et al. this volume). Here, the authors show that China currently has a relatively low average adaptive capacity compared to the UK, USA and Australia. Furthermore, 17 out of its 31 provinces have adaptive capacities below this relatively low national average level, with eastern provinces having higher levels than central and western provinces. Li et al. (this volume) build on this study to model the vulnerability of agriculture to climate change in China, showing that provinces in southwest China are particularly vulnerable by the 2040s due to varying combinations of exposure, sensitivity and adaptive capacity.

In addition to developing new insights into climate change impacts, adaptation and vulnerability, CLIMSAVE has also considered the costs and potential of adaptation options, which are important for effective decision-making in the face of climate change. However, cross-sectoral effects of adaptation measures are rarely taken into 
consideration in adaptation costing and cost-effectiveness analysis. Therefore, Skourtos et al. (this volume) developed and applied a new analytical tool, 'CrossAdapt', to elicit expert judgment on the cross-sectoral effects of proposed adaptation measures in the six CLIMSAVE sectors. The application of CrossAdapt shows that the calculation of cross-sectoral impacts and their integration into cost-effectiveness analysis can significantly affect the cost-effectiveness ranking of adaptation measures. These results are incorporated within the cost-effectiveness screen of the IA Platform along with the relative costs, capital requirements, applicability and effectiveness of specific adaptation options. It remains impossible, with the current state of knowledge, to derive robust monetary measures of the cost-effectiveness of adaptation options at the European scale and how these might alter if cross-sectoral impacts are taken into account. The cost-effectiveness analysis is therefore restricted to a qualitative description that helps platform users to think about adaptation options, while leaving the numerical focus on impacts that are estimated more rigorously, and in a spatial framework, in the other screens of the platform.

\subsection{Policy implications}

The EU White Paper on "Adapting to climate change: Towards a European framework for action" $(\operatorname{COM}(2009) 147)$, stated that the EU is committed to "implementing adaptation to reduce the EU's vulnerability to the impact of climate change". The assessment of future climate change impacts and vulnerabilities, however, are subject to a number of uncertainties including those arising from the modelling and the underlying datasets, the assumptions about scenario parameters, especially those affecting alternative socio-economic development pathways, and the magnitude of error propagation through integrated modelling systems. The CLIMSAVE IA Platform has sought to capture some of these by formally identifying and quantifying these sources of uncertainty (Brown et al. this volume; Dubrovsky et al. this volume; Kok et al. this volume; Dunford et al. 2014), thus enabling the exploration of the robustness of alternative policy response strategies (Jäger et al. this volume).

The importance of taking the inherent and unavoidable uncertainty in future climate and socio-economic conditions into account, as well as uncertainty due to error propagation in integrated assessment models, has been demonstrated by Dunford et al. (2014) using formal numerical approaches, modeller interviews and network analysis. Brown et al. (this volume) explored model and scenario uncertainty through a probabilistic uncertainty analysis of selected IA Platform output metrics. They found that, at the aggregate European scale, uncertainty ranges associated with the sectoral or ecosystem service output values for the four CLIMSAVE socio-economic scenarios were not consistently distinct from one another, thus suggesting that climate-related uncertainty had a larger effect than socio-economic-related uncertainty on the metrics. Nevertheless, there was evidence that particular adaptation actions may significantly alter climate change impacts, especially at the national to local scales.

Given these uncertainties about future climate change and socio-economic development there is a need to identify robust policy responses (Jäger et al. this volume). In that study, the authors defined a robust policy measure as one which has benefits (in terms of an improvement in human well-being through a reduction of vulnerability to climate and socio-economic change) across sectors, scenarios and spatial scales. Adaptation options were clustered into four policy archetypes: Ecosystem-based Adaptation (EbA), Market-based Adaptation (MbA), Technology-based Adaptation 
$(\mathrm{TbA})$ and People-based Adaptation $(\mathrm{PbA})$. The IA Platform was then run without any adaptation and with each of the policy archetypes. The People-based archetype was found to be the most robust as it includes options that increase both human and social capital, which thus increases coping capacity.

In addition to identifying robust adaptation options, the need for sectors to take action on both adaptation and mitigation and to realise the synergies between them was recognised in the EU Strategy on Adaptation to Climate Change (EC 2013). A review of adaptation and mitigation measures undertaken within the six sectors in the IA Platform showed that many synergies and conflicts are not explicitly acknowledged and taken into account when considering their impacts (Berry et al. this volume). The authors found that many of the synergies and conflicts involved biodiversity and water, thus, these sectors may represent important ones for further investigation of the potential opportunities to realise synergies and avoid conflicts. If effective action is to be taken, including mainstreaming adaptation and mitigation into policy, then the cross-sectoral synergies and conflicts should be identified and addressed, which might require greater coordination of governance.

\section{Conclusions}

The CLIMSAVE project has developed and applied a regional participatory IA tool for Europe called the CLIMSAVE IA Platform. The Platform addresses the need for holistic assessments of the effects of our changing climate which take account of stakeholder requirements, the effects of both climate and socio-economic change, and cross-sectoral interactions. It allow users to explore the complex issues surrounding impacts, vulnerability and adaptation to climate change at regional and European scales through four screens: (1) Impacts - how different amounts of future climate and socio-economic change may affect urban, rural and coastal areas, agriculture, forestry, water and biodiversity; (2) Vulnerability - which areas or 'hotspots' in Europe may be vulnerable to climate change under a specified scenario, before and after adaptation; (3) Adaptation - how adaptation options can reduce the impacts of climate change; and (4) Cost-effectiveness - the relative cost and potential of adaptation measures to reduce the impacts of climate change.

This Special Issue describes the many challenges in participatory IA and demonstrates the benefits of the integrated CLIMSAVE approach for improving understanding of climate change impacts, vulnerability and adaptation at multiple scales. The integration of top-down impact, vulnerability and adaptation modelling and bottom-up scenario development processes within the CLIMSAVE approach has improved the representation of adaptation in such modelling, by incorporating scenario-specific storylines and capital constraints. However, there are likely to be further benefits in understanding to be gained by incorporating an improved representation of human decision-making and policy processes associated with adaptation for regional integrated assessment. Furthermore, the Platform is not intended to provide detailed local predictions, but to assist stakeholders in developing their capacity to address regional/ national/EU scale issues surrounding climate change. It is, thus, intended to complement, rather than replace, the use of more detailed sectoral tools used by sectoral professionals and academics. The Platform is aimed at a broad target group of professional, academic and governmental stakeholders through free web access and an interactive, exploratory and user-friendly interface. It is also expected to be a 
valuable teaching tool which contributes to a better adapted Europe through assisting the intellectual development of future decision-makers in understanding cross-sectoral implications of a diverse range of uncertain futures across Europe.

Acknowledgments The research leading to these results has received funding from the European Commission Seventh Framework Programme under Grant Agreement No. 244031 (The CLIMSAVE Project; Climate change integrated assessment methodology for cross-sectoral adaptation and vulnerability in Europe; www.climsave.eu). CLIMSAVE is an endorsed project of the Global Land Project of the IGBP. The authors would like to thank all CLIMSAVE partners for their contributions to many productive discussions which are reflected in this Special Issue.

\section{References}

Alcamo J (2008) Environmental futures: the practice of environmental scenario analysis. Developments in Integrated Environmental Assessment - Volume 2. Elsevier, Amsterdam

Audsley E, Trnka M, Sabaté S, Sanchez A (this volume) Interactively modelling land profitability to estimate European agricultural and forest land use under future scenarios of climate, socio-economics and adaptation. Clim Change doi:10.1007/s10584-014-1164-6

Berry PM, Brown S, Chen M, Kontogianni A, Rowlands O, Simpson G, Skourtos M (this volume) Crosssectoral interactions of adaptation and mitigation measures. Clim Change doi:10.1007/s10584-014-1214-0

Brown E, Brown C, Murray-Rust D, Cojocaru G, Savin C, Rounsevell MDA (this volume) Analysing uncertainties in climate change impact assessment across sectors and scenarios. Clim Change doi:10.1007/ s10584-014-1133-0

Chen M, Sun F, Berry P, Tinch R, Ju H, Lin E (this volume) Integrated assessment of China's adaptive capacity to climate change using a capital approach. Clim Change doi:10.1007/s10584-014-1163-7

Dempsey R, Fisher A (2005) Consortium for Atlantic regional assessment: information tools for community adaptation to changes in climate and land use. Risk Anal 25(6):1495-1509

Dittrich Y, Lindeberg L (2004) How use-oriented development can take place. Inf Softw Technol 46:603-617

Dubrovsky M, Trnka M, Svobodova E, Holman IP (this volume) Developing a reduced-form ensemble of climate change scenarios for Europe and its application to selected impact indicators. Clim Change doi:10. 1007/s10584-014-1297-7

Dunford R, Harrison PA, Rounsevell, MDA (2014) Exploring scenario and model uncertainty in cross-sectoral integrated assessment approaches to climate change impacts. Clim Change. doi:10.1007/s10584-014-1211-3

Dunford R, Harrison PA, Jäger J, Rounsevell MDA, Tinch R (this volume) Exploring climate changevulnerability across sectors and scenarios through indicators of impacts and coping capacity. Clim Change doi:10.1007/s10584-014-1162-8

EEA (2010) The European Environment, state and outlook 2010. Assessment of global megatrends. EEA, Copenhagen

EC (2009) White paper on adapting to climate change: towards a european framework for action. European Commission (COM(2009) 147), Brussels

EC (2013) An EU strategy on adaptation to climate change. European Commission (COM(2013) 216), Brussels

Gramberger M, Zellmer K, Kok K, Metzger M (this volume) Stakeholder Integrated Research (STIR): a new approach tested in climate change adaptation research. Clim Change doi:10.1007/s10584-014-1225-x

Hanson CE, Palutikof JP, Dlugolecki A, Giannakopoulos C (2006) Bridging the gap between science and the stakeholder: the case of climate change research. Clim Res 31(1):121-133

Harrison PA, CLIMSAVE consortium (2013). Climate change impacts, adaptation and vulnerability in Scotland: an integrated approach. CLIMSAVE Policy Brief, TIAMASG, Bucharest. Available from http://www. climsave.eu/climsave/doc/Policy_Brief_for_Scotland.pdf. Accessed 1 May 2014

Harrison PA, Holman IP, Cojocaru $\bar{G}$ et al (2013) Combining qualitative and quantitative understanding for exploring cross-sectoral climate change impacts, adaptation and vulnerability in Europe. Reg Environ Change 13:761-780

Harrison PA, Dunford R, Savin C-M, Rounsevell MDA, Holman IP, Kebede AS, Stuch B (this volume) Crosssectoral impacts of climate change and socio-economic change for multiple European land- and water-based sectors. Clim Change doi:10.1007/s10584-014-1239-4

Holman IP, Harman J (2008) Preliminary evaluation of the benefits of a participatory regional integrated assessment software. Clim Change 90(1-2):169-187 
Holman IP, Rounsevell MDA, Cojacaru G, Shackley S, McLachlan C, Audsley E, Berry PM, Fontaine C, Harrison PA, Henriques C, Mokrech M, Nicholls RJ, Pearn KR, Richards JA (2008) The concepts and development of a participatory regional integrated assessment tool. Clim Change 90:5-30

Holman IP, Cojocaru G, Harrison PA (2013) Guidance report describing the final version of the CLIMSAVE integrated assessment platform. CLIMSAVE Deliverable D2.4. Available from http://www.climsave.eu/ climsave/doc/Report_on_the_Final_IA_Platform.pdf. Accessed 1 May 2014

Holman IP, Harrison PA, Metzger M (2014) Cross-sectoral impacts of climate and socio-economic change in Scotland - implications for adaptation policy. Reg Environ Change. doi:10.1007/s10113-014-0679-8

Jäger, J, Rounsevell MDA, Harrison PA, Dunford R, Fuchs D, Omann I, Pataki G (this volume) Assessing policy robustness of climate change adaptation measures across sectors and scenarios. Clim Change doi:10.1007/ s10584-014-1240-y

Kebede AS, Dunford R, Audsley E, Harrison PA, Holman IP, Mokrech M, Nicholls RJ, Rickebusch S, Rounsevell MDA, Sabaté S, Sallaba F, Sanchez A, Savin C-M, Trnka M, Wimmer F (this volume) Direct and indirect impacts of climate and socio-economic change in Europe: a sensitivity analysis for key landand water-based sectors. Clim Change doi:10.1007/s10584-014-1313-y

Kok K, Sendzimir J, Bärlund I, Flörke M, Gramberger M, Zellmer K, Stuch B, Holman IP (this volume) European participatory scenario development: strengthening the link between stories and models. Clim Change doi: 10.1007/s10584-014-1143-y

Li Y, Xiong W, Ju H, Berry P, Wang W, Lin E (this volume) Integrated assessment of China's agricultural vulnerability to climate change: a multi-indicator approach. Clim Change doi:10.1007/s10584-014-1165-5

Mokrech M, Kebede AS, Nicholls RJ, Wimmer F (this volume) An integrated approach for assessing flood impacts due to future climate and socio-economic conditions and the scope of adaptation in Europe. Clim Change doi:10.1007/s10584-014-1298-6

Pahl C (2004) Adaptive development and maintenance of user-centric software systems. Inf Softw Technol 46: 973-986

Pataki G, High C, Nemes G (2012) Report on the policy and governance context for adaptation. Deliverable D1.1 from the EU CLIMSAVE Project. http:/www.climsave.eu/climsave/doc/Report_on_the_adaptation_policy_ analysis.pdf. Accessed 1 May 2014

Salter J, Robinson J, Wiek A (2010) Participatory methods of integrated assessment - a review. WIREs Climat Chang 1:697-717

Skourtos M, Kontogianni A, Tourkolias C (2013) The CLIMSAVE adaptation cost database. Athens. Available at: http://www.climsave.eu/climsave/index.htm. Accessed 1 May 2014

Skourtos M, Tourkolias Ch, Kontogianni A, Damigos D, Harrison PA, Berry PM (this volume) Internalizing cross-sectoral effects into cost-effectiveness adaptation analysis. Clim Change doi:10.1007/s10584-0141168-2

Tinch R, Jäger, J, Omann I, Harrison PA, Wesely J, Dunford R (this volume) Applying a capitals framework to measuring coping and adaptive capacity in integrated assessment models. Clim Change doi:10.1007/s10584014-1299-5

Turnpenny J, Haxeltine A, O'Riordan T (2004) A scoping study of user needs for integrated assessment of climate change in the UK context: part 1 of the development of an interactive integrated assessment process. Integr Assess 4:283-300

Van't Klooster SA, Van Asselt MBA (2006) Practising the scenario-axes technique. Futures 38:15-30

Wimmer F, Audsley E, Savin C-M, Malsy M, Dunford R, Harrison PA, Schaldach R, Flörke M (this volume) Modelling the effects of cross-sectoral water allocation schemes in Europe. Clim Change doi:10.1007/ s10584-014-1161-9 